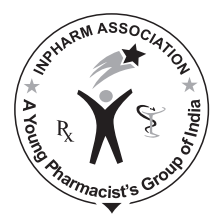

\title{
Preliminary Phytochemical Screening and Antispasmodic Activity of Artemisia macrocephala Jacquem
}

\author{
Ali $\mathbf{N}^{1,2}$, Shah SWA ${ }^{2}$, Shah $\mathbf{I}^{2}$ \\ ${ }^{1}$ Institute of Basic Medical Sciences, Khyber Medical University, Peshawar, Khyber Pakhtunkhwa, Pakistan, \\ ${ }^{2}$ Department of Pharmacy, University of Malakand, Chakdara, Dir. Khyber Pakhtunkhwa, Pakistan
}

Address for correspondence: Dr Niaz Ali; E-mail: niazpharmacist@yahoo.com

\begin{abstract}
The current work describes the antispasmodic action of Artemisia macrocephala, which is achieved via blocking of the calcium channels. This explains its traditional use as an antispasmodic. The crude methanolic extract of $A$. macrocephala was studied for possible relaxant effect(s) on spontaneous rabbits' jejunum preparations. Analytical-grade chemicals were used in the experimental protocols. A. macrocephala gave positive tests for flavonoids, saponins, glycosides, alkaloids, and terpenes. A. macrocephala caused relaxation of spontaneous rabbits' jejunum preparations $(n=6)$ at a dose of $10.0 \mathrm{mg} / \mathrm{mL}\left(\mathrm{EC}_{50}=6.95 \pm 0.20 \mathrm{mg} / \mathrm{mL} ; 95 \% \mathrm{Cl}: 6.2\right.$ to 7.5$)$. Contractions induced by $80 \mathrm{mM}$ potassium chloride $(\mathrm{KCl})$ were also relaxed by the $A$. macrocephala at dose of $10.0 \mathrm{mg} / \mathrm{mL}$. Attempting to find an explanation for the possible mode of action, we found that, A. macrocephala at concentration of $1.0 \mathrm{mg} / \mathrm{mL}$ produced rightward shift in the calcium chloride curves, with $\mathrm{EC}_{50}$ value of -1.65 $\pm 0.02 \log \left[\mathrm{Ca}^{++}\right] \mathrm{M}$ vs control with $\mathrm{EC}_{50}$ value of $-2.44 \pm 0.043$ for calcium chloride curves. At a concentration of $1.0 \mathrm{mg} / \mathrm{mL}$ it could produce $52.4 \%$ of the control response at $\log \left[\mathrm{Ca}^{++}\right] \mathrm{M}=-1.6$. Similarly, verapamil at a concentration of $0.1 \mu \mathrm{M}$ produced a rightward shift, with $\mathrm{EC}_{50}$ value of $-1.74 \pm 0.026 \log \left[\mathrm{Ca}^{++}\right] \mathrm{M}(95 \% \mathrm{Cl}:-1.66$ to $-1.82 ; n=6)$ vs control with $\mathrm{EC}_{50}$ value of $-2.45 \pm 0.05 \log \left[\mathrm{Ca}^{++}\right] \mathrm{M}(95 \% \mathrm{Cl}:-2.23$ to $-2.91 ; n=6)$. The right shift of the $\mathrm{EC}_{50}$ values is justification for the folkloric use of $A$. macrocephala as an antispasmodic, suggesting that the possible mode of action is through calcium channel blockade.
\end{abstract}

Key words: Antispasmodic, Artemisia macrocephala, calcium channel blocking activity, folkloric use, verapamil

\section{INTRODUCTION}

Artemisia macrocephala (Synm: Artemisia griffithiana Boiss.) belongs to family Asteraceae. ${ }^{[1]}$ The genus Artemesia has

\begin{tabular}{|l|l|}
\hline \multicolumn{2}{|c|}{ Access this article online } \\
\hline Quick Response Code: & \\
\hline & Website: \\
& www.jyoungpharm.in \\
& \\
\hline
\end{tabular}

wide use as a phytomedicine. Artemeisia judaica is used in the treatment of itching, wounds, and congestion. ${ }^{[2]}$ The leaves of Artemisia stelleriana Bess. are used as a carminative and in the treatment of peptic ulcer. ${ }^{[2]}$ The hepatoprotective activity of Artemisia maritima has been also documented. ${ }^{[3]}$ So far, essential oils that have been reported from $A$. macrocephala include $\alpha$ - and $\beta$-pinenes, camphene, $\Delta^{3}$-carene, limonene, $\mathrm{p}$-cymene, 1,8 cineole, camphor, and borneol. ${ }^{[4]}$ Traditionally, fresh leaves of A. macrocephala have been used in the treatment of dysentery. The juice of fresh leaves of $A$. macrocephala are also used as an anti-allergic and antispasmodic ${ }^{[1]}$ Because of the many literature reports regarding the folkloric uses 
of A. macrocephala as an antispasmodic, we carried out our current work to scientifically study the species for its possible modes of action(s).

\section{MATERIALS AND METHODS}

\section{Collection and identification of plant materials}

The dried aerial parts of $A$. macrocephala was collected in the month of April-May, 2009, from the nearby hills (Badwan Chowk) of campus-I of the University of Malakand, Chakdara, Dir Lower, Khyber Pakhtunkhwa, Pakistan. The plant was identified by professor Dr Jehandar Shah, plant taxonomist and Vice Chancellor, Shaheed Benazir Bhutto University, Dir Upper, Sheringal. A voucher specimen, AM-01-2009, has been submitted to the herbarium of the University of Malakand.

\section{Preparation of methanolic extract}

The shade-dried aerial parts of $A$. macrocephala were soaked in commercial-grade methanol and subjected to occasional shaking. After 15-20 days, the suspension was filtered. This process was repeated thrice. The filtrates were combined and concentrated under reduced pressure using a rotary evaporator at a temperature of $40^{\circ} \mathrm{C}$. A greenish-black extract was obtained, which was used in the pharmacological screening(s).

\section{Drugs and animals}

All the solutions were prepared in distilled water on the day of the experiments. Acetylcholine was purchased from BDH Chemicals, Poole, England. The rest of the chemicals were purchased from E. Merck, Germany. Rabbits of either sex were used in the experiments. The animals had free access to water. They were kept in fasting conditions 24 hours prior to the start of the experiments. The animals were treated as per the Animals Bylaws - 2008 of the University of Malakand (Scientific Procedures Issue-1), complying with international standards for handling the laboratory animals. The study protocol was duly approved by the legal bodies of the University of Malakand.

\section{Data recording}

Graph tracings related to intestinal responses were recorded using an isotonic force transducer (Model No: MLT 0210/A Pan Lab S.I.) connected with PowerLab ${ }^{\circledR}$ (Model No: 4/25 T; AD Instruments, Australia) through a bridge pod amplifier. Other setting parameters were at range of $20 \mathrm{mV}$, low pass $10 \mathrm{~Hz} \times 10$ gain using input 1 , rate 40/s.
Interpretation of graph tracings, calculation, and statistical analysis

Chart 5 for Windows ${ }^{\circledR}$ supplied with PowerLab ${ }^{\circledR}$ was used to interpret the graph tracings. The mean $\mathrm{EC}_{50}$ values were calculated with the $95 \%$ confidence intervals. Student's $t$ test was used for assessing the significance of differences.

\section{Preliminary phytochemical screening}

Preliminary phytochemical screening for the presence of terpenes, flavonoids, tannins, saponins, alkaloids, anthraquinone glycosides, and cardiac glycosides was performed as per reported procedures. ${ }^{[5,6]}$

\section{Effects on spontaneous rabbits' jejunum preparations}

Effects of $A$. macrocephala on spontaneous jejunum preparations were performed as per the procedure of Gilani et al. and a previous work of ours. ${ }^{[7,8]}$ Rabbits were given a blow on the cervix to cause cervical dislocation. Their abdomens were opened. A portion of jejunum was isolated and maintained in a petri dish aerated with carbogen gas. Pieces of rabbit jejunum of about $1-1.5 \mathrm{~cm}$ in length were mounted in a tissue organ bath containing Tyrode's solution. The tissues were allowed to become stable for at least $30 \mathrm{~min}$. The crude methanolic extract was tested in concentrations of $0.01,0.03,0.1,0.3,1.0$, $3.0,5.0$, and $10.0 \mathrm{mg} / \mathrm{mL}$. The responses were recorded. The experiments were performed six times. Concentrations ( $\mathrm{mM}$ ) of the constituents of Tyrode's solution were as follows: $\mathrm{KCl} 2.68, \mathrm{NaCl} 136.9, \mathrm{MgCl}_{2} 1.05, \mathrm{NaHCO}_{3}$ 11.90, $\mathrm{NaH}_{2} \mathrm{PO}_{4} 0.42, \mathrm{CaCl}_{2} 1.8$, and glucose 5.55. All the experimental protocols were carried out at $37 \pm 1^{\circ} \mathrm{C}$. Similarly, the effects on $\mathrm{KCl}(80 \mathrm{mM})$-induced contractions in rabbits' jejunum preparations were also recorded to clarify the possible mode of action. The rabbits' jejunum tissues were maintained in a state of sustained contraction by $\mathrm{KCl} 80 \mathrm{mM}$ in organ bath that was constantly bubbled with carbogen gas at $37 \pm 1^{\circ} \mathrm{C}$. The crude methanolic extract was tried in similar fashion as per reported work. ${ }^{[7,8]}$

\section{Effects on calcium channels}

In order to explain the possible mode of action on rabbits' jejunum preparations, we constructed calcium curves for the tissues treated with different concentrations of $A$. macrocephala in a decalcifying medium. ${ }^{[7,8]}$ For confirmation of calcium channel blocking activity, the tissues were exposed to calcium-free Tyrode's solution containing EDTA (0.1 mM). This was followed by experiments in potassium-rich Tyrode's solution with the following 
composition (mM): $\mathrm{KCl} 50, \mathrm{NaCl} 91.04, \mathrm{MgCl}_{2} 1.05$, $\mathrm{NaHCO}_{3}$ 11.90, $\mathrm{NaH}_{2} \mathrm{PO}_{4}$ 0.42, glucose 5.55, and EDTA 0.1 . Prior to this, all the tissues were stabilized in normal Tyrode's solution for at least $30 \mathrm{~min}$. Calcium response curves were constructed in the decalcified tissues with the cumulative addition of $\mathrm{Ca}^{++}$at concentrations of $1 \times 10^{-4}$ to $256 \times 10^{-4} \mathrm{M}$.

\section{RESULTS}

\section{Phytochemical screening}

A. macrocephala tested positive for alkaloids, flavonoids, saponins, and terpenes. However, A. macrocephala tested negative for tannin, cardiac glycosides, and anthraquinone glycosides.

Effects on spontaneous and $\mathrm{KCl}$-induced contractions on rabbits'

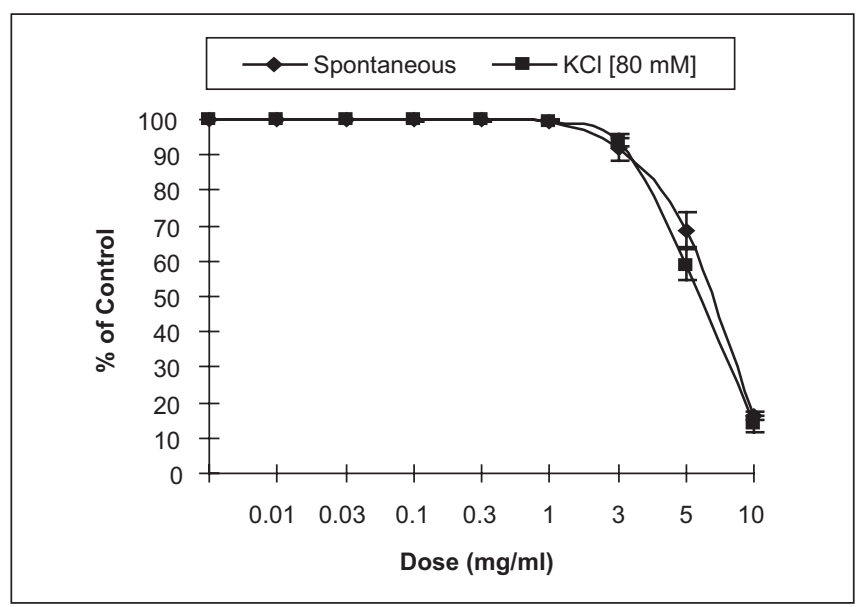

Figure 1: Relaxing effects of crude methanolic extract of $A$. macrocephala on spontaneous rabbits' jejunum preparations and $\mathrm{KCl}$-induced contractions jejunum preparations: The effects of $A$. macrocephala are shown in Figure 1. A. macrocephala produced a relaxant effect on spontaneous rabbits' jejunum preparations $(n=6)$ with mean $\mathrm{EC}_{50}$ value of $6.95 \pm 0.20 \mathrm{mg} / \mathrm{mL}$ (95\% CI: 6.2 to 7.5 ). There was maximum relaxation at the concentration of $10.0 \mathrm{mg} / \mathrm{mL}$. High-concentration $(80 \mathrm{mM}) \mathrm{KCl}$-induced contractions were also relaxed by $A$. macrocephala in a similar fashion. The effects on KCl-induced contractions and on spontaneous rabbits' jejunum preparations are suprimposible [Figure 1].

\section{Calcium channel blocking activity}

Positive relaxant effects by a test drug or an extract does not always indicate calcium channel blockade. ${ }^{[9]}$ Plotting of calcium chloride curves helps confirm whether the mode of action is through the calcium channels. A. macrocephala at a concentration of $1.0 \mathrm{mg} / \mathrm{mL}$ produced a rightward shift in the calcium chloride curves [Figure 2a] with $\mathrm{EC}_{50}$ value of $-1.65 \pm 0.02 \log \left[\mathrm{Ca}^{++}\right] \mathrm{M}$ vs control, with $\mathrm{EC}_{50}$ value of $-2.44 \pm 0.043$. A. macrocephala at a concentration of 1.0 $\mathrm{mg} / \mathrm{mL}$ could produce $52.4 \%$ of the control response at $\log \left[\mathrm{ca}^{++}\right] \mathrm{M}=-1.6$. Similarly, verapamil at a concentration of $0.1 \mu \mathrm{M}$ [Figure 2b] produced a rightward shift, with $\mathrm{EC}_{50}$ value of $-1.74 \pm 0.026 \log \left[\mathrm{Ca}^{++}\right] \mathrm{M}(95 \% \mathrm{CI}:-1.66$ to $-1.82 ; n=6)$ vs control with $\mathrm{EC}_{50}$ value of $-2.45 \pm 0.05$ $\log \left[\mathrm{Ca}^{++}\right] \mathrm{M}(95 \% \mathrm{CI}:-2.23$ to $-2.91 ; n=6)$.

\section{DISCUSSION}

In view of the traditional use of $A$. macrocephala as an antispasmodic, its extract was tested for possible inhibitory effects on spontaneous rabbits' jejunum preparations. Positive relaxing effects on the spontaneous rabbits' jejunum preparations confirmed its antispasmodic action.

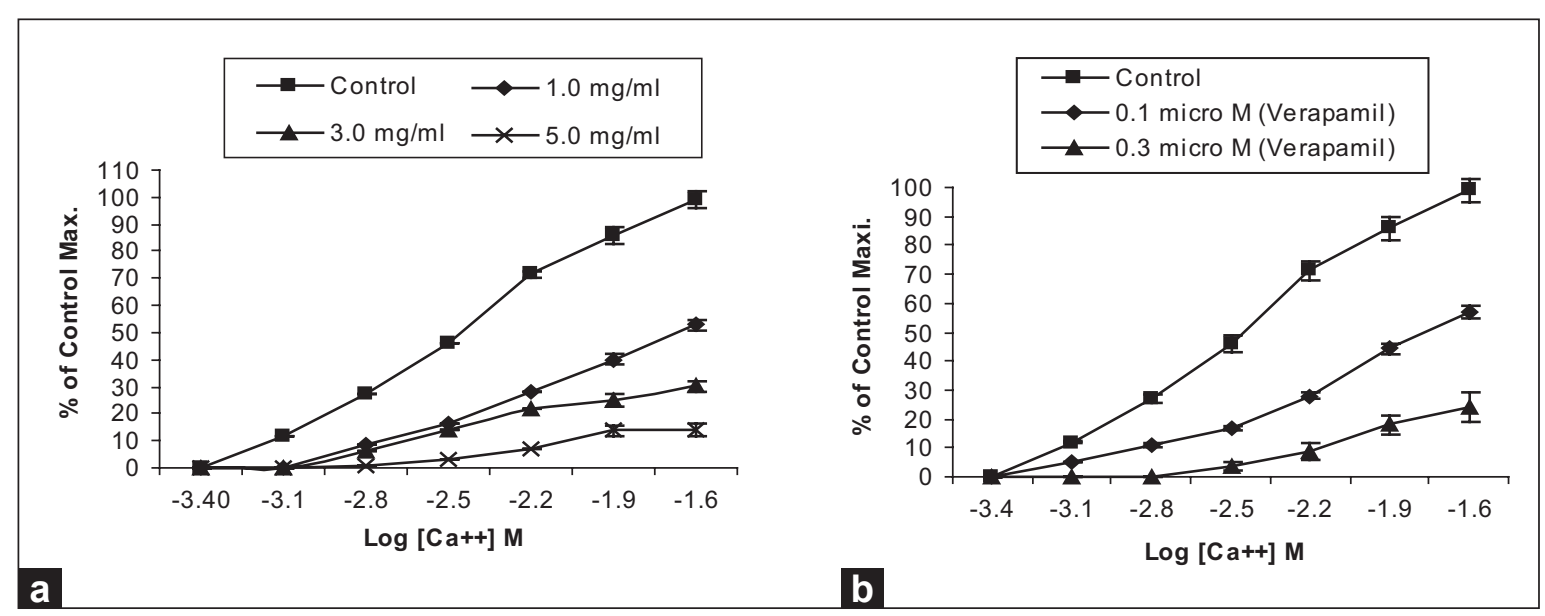

Figure 2: Calcium chloride curves in absence and presence of increasing doses of (a) Crude methanolic extract of $A$. macrocephala and (b) verapamil in isolated rabbits' jejunum preparations 


\section{Ali, et al.: Exploring A. macrocephala}

Positive relaxing effects on $\mathrm{KCl}$-induced contractions suggested that the possible mode of action may be through calcium channel blockade. ${ }^{[7,8]}$ There is usually an exchange of calcium between extracellular and intracellular stores. Moreover, the voltage-dependent calcium channels are responsible for the periodic depolarization and repolarization of the intestinal tissues that maintains its spontaneous contractions. Drugs that block these channels in the intestines will have a relaxing effect. ${ }^{[10-13]}$ Plotting of calcium chloride curves in the extract-treated tissues proved that the relaxing effects are through calcium channel blockade. Comparison with the curves of calcium chloride in verapamil-treated tissues confirmed that the mode of action of the extract was through other calcium channels because of the right shift in the $\mathrm{EC}_{50}$ values. ${ }^{[14]}$

\section{CONCLUSION}

Thus, we conclude that $A$. macrocephala has an antispasmodic action through the calcium channel blocking mechanism, which justifies its folkloric use as an antispasmodic. The antispasmodic action may be attributed to the presence of active phytochemical constituents in the plant. Further work is necessary for activity-guided isolation of the pharmacologically active substances.

\section{REFERENCES}

1. Ahmad S, Ali A, Bibi S, Marwat KB, Hassan G. Ethnobotanical study on some medicinal plants of Ouch District Dir, Pakistan. Pak J Pl Sci 2006;12:65-71.
2. Wiart C. Ethnopharmacology of Medicinal plants. Asia and the Pacific. $1^{\text {st }}$ ed. Totowa, New Jersey: Humana Press; 2006. p. 14, 98.

3. Janbaz KH, Gilani AH. Evaluation of the protective potential of Artemisia maritima extract on acetaminophen and $\mathrm{CCl}_{4}$-induced liver damage. J Ethnopharmacol 1995;47:43-7.

4. Dudko VV, Berezov skya TP, Vsynina RV. Essential oil from Artemisia macrocephala. Him Prir Soedin 1994;1:100.

5. Aduragbenro DA, Yeside OO, Adeolu AA, Olanrewaju MJ, Ayotunde $\mathrm{SA}$, Olumayokun AO, et al. Blood pressure lowering effect of Adenanthera pavonina Seed extract on normotensive rats. Rec Nat Prod 2009;3:282-9.

6. Edeoga, HO, Okwu DE, Mbebie BO. Phytochemical constituents of some Nigerian medicinal plants. Afr J Biotechnol 2005;4:685-8.

7. Gilani AH, Bukhari IA, Khan RA, Khan A, Ullah F, Ahmad VU. Cholinomimetic and Calcium Channel Blocking Activities of Carthamus oxycantha. Phytother Res 2005;19:679-83.

8. Niaz A, Bashir A, Shumaila B, Jehandar S, Sadiq A, Manzoor A. Calcium channel blocking activities of Withania coagulans. Afr J Pharma Pharmacol 2009;3:439-42.

9. Kobayashi K, Ishihara T, Khono E, Miyase T, Yoshizaki F. Constituents of stem bark of Callistemon rigidus showing inhibitory effects on mouse alpha- amylase activity. Biol Pharm Bull 2006;29:1275-7

10. Bolton TB. Mechanism of action of transmitter and other substances on Smooth muscles. Physiol Rev 1979;59:606-18.

11. Karaki H, Wiess G. Mini-review: Calcium release in smooth muscles. Life Sci 1983;42:111-2.

12. Godfraind T, Miller R, Wibo M. Calcium antagonism and calcium entry blockade. Pharmacol Rev 1986;38:321-416.

13. Carl A, Lee HK, Sanders KM. Regulation of ion channels in smooth muscles by calcium (Invited Review). Am J Physiol 1996;271:C9-34.

14. Cortes AR, Delgadillo AJ, Hurtado M, Dominguez-Ramirez AM, Medina JR, Aoki K. The antispasmodic activity of Buddleja scordioides and Buddleja perfoliata on isolated intestinal preparations. Biol Pharm Bull 2006;29: 1186-90.

Cite this article as: Ali N, Shah SA, Shah I. Preliminary phytochemical screening and antispasmodic activity of Artemisia macrocephala jacquem. $\mathrm{J}$ Young Pharmacists 2011;3:125-8.

Source of Support: Nil, Conflict of Interest: None declared. 